\title{
Stem/Progenitor Cells in Non-Lactating Versus Lactating Equine Mammary Gland
}

\author{
Jan H. Spaas, ${ }^{1}$ Koen Chiers, ${ }^{2}$ Leen Bussche, ${ }^{1}$ Christian Burvenich, ${ }^{1}$ and Gerlinde R. Van de Walle ${ }^{1}$
}

The mammary gland is a highly regenerative organ that can undergo multiple cycles of proliferation, lactation, and involution. Based on the facts that (i) mammary stem/progenitor cells (MaSC) are proposed to be the driving forces behind mammary growth and function and (ii) variation exists between mammalian species with regard to physiological and pathological functioning of this organ, we believe that studying MaSC from different mammals is of great comparative interest. Over the years, important data has been gathered on MaSC of men and mice, although knowledge on MaSC in other mammals remains limited. Therefore, the aim of this work was to isolate and characterize MaSC from the mammary gland of horses. Hereby, our salient findings were that the isolated equine cells met the 2 in vitro hallmark properties of stem cells, namely the ability to self-renew and to differentiate into multiple cell lineages. Moreover, the cells were immunophenotyped using markers for CD29, CD44, CD49f, and Ki67. Finally, we propose the mammosphere assay as a valuable in vitro assay to study MaSC during different physiological phases since it was observed that equine lactating mammary gland contains significantly more mammosphere-initiating cells than the inactive, nonlactating gland (a reflection of MaSC selfrenewal) and, moreover, that these spheres were significantly larger in size upon initial cultivation (a reflection of progenitor cell proliferation). Taken together, this study not only extends the current knowledge of mammary gland biology, but also benefits the comparative approach to study and compare MaSC in different mammalian species.

\section{Introduction}

$\mathrm{T}$ HE MAMMARY GLAND IS A UNIQUE organ because, although the stroma is established prior to birth, the mammary epithelium primarily develops postnatal and achieves full maturity in the adult pregnant individual [1]. In general, from birth till after puberty, the mammary gland remains rudimentary with a relatively quiescent growth mainly consisting of ductal elongation [2]. Once pregnancy is initiated, this dynamic organ will undergo intensive remodeling with (i) alveolar growth and secretory differentiation, (ii) lactation, with milk secretion, and (iii) involution, with apoptosis and regression [2,3]. Growing evidence suggests that these changes are driven by the coordinated division and differentiation of mammary stem cell populations [2,4,5]. In 1986, Soule and McGrath penicillin reported for the first time the existence of undifferentiated human mammary cells that could survive in suspension [6]. A couple of years later, these cells were designated human mammary stem/progenitor cells (MaSC) and showed properties of bipotent cells based on their capacity to produce adult luminal epithelial and myoepithelial cells $[7,8]$. Now, if MaSC are indeed the driving force behind the different remodeling phases, then it could be anticipated that the number or proliferation rate of MaSC might vary depending on the physiological stage of this dynamic organ.

For understanding the functional role of MaSC in normal mammary gland development, the cleared fat pad mouse model is frequently used $[9,10]$. This in vivo model allows the transplantation and growth of mammary cells into their normal anatomical site and under the influence of a normal physiological environment [10]. Using this model, it has for example, been demonstrated that MaSC are a relative quiescent cell type, which only becomes activated under conditions of mammary gland repopulation such as fetal growth or the pubertal growth phase [10-13]. Also, this murine mammary gland-free fat pad transplantation system is the animal model of choice for human breast cancer research [14]. Indeed, mice have played an indispensable and pivotal role in the study of breast cancer and this animal species will keep on being a major research resource in comprehending this devastating disease [15]. However, by studying (patho)physiological mechanisms in such model, some key insights might be lost due to the absence of variation. Intriguingly, whereas both in humans and other mammals, the

${ }^{1}$ Departments of Comparative Physiology and Biometrics and ${ }^{2}$ Pathology, Bacteriology and Poultry Diseases, Faculty of Veterinary Medicine, Ghent University, Merelbeke, Belgium. 
mammary gland undergoes repeated cycles of development, function, and dedifferentiation, changes proposed to be driven by MaSC, and the incidence of mammary cancer greatly varies among these species. Mammary cancer is common in humans and carnivores [16], whereas cows, sheep, pigs, and horses only very rarely develop mammary tumors [17]. We now believe that using this variation among different animal species, namely the susceptibility for mammary gland cancer, might provide novel insights into the mechanisms underlying the functional behavior and regulation of MaSC. Therefore, we believe it is of eminent importance to study MaSC in as many species as possible.

In general, a thorough study on the isolation and characterization of MaSC is a critical step toward elucidating MaSC functioning under different physiological and pathological circumstances in different species. Unfortunately, when looking at companion or production animals, not much information on MaSC is available to date. This is primarily due to the lack of universal markers and in vitro systems to identify MaSC in different mammals. Moreover, functional in vivo assays to detect MaSC activity are missing in these species, emphasizing the need for developing additional in vitro assays to better characterize these cells. Several reports describe the isolation and characterization of MaSC from mammary gland tissues of dogs, mostly to gain better insights into mammary tumorogenesis [18-20], a process that shares many features with human breast cancer [21-23]. In cattle, on the other hand, MaSC are being studied mainly to explore their potential to improve milk production efficiency [1,24-27]. In horses, however, the knowledge on mammary gland development is mainly limited to lactation physiology [28-30] and no information on MaSC in this species is available to date, although a thorough study of equine MaSC could potentially extend the current knowledge of mammary gland biology and will aid in our comparative physiological approach to study and compare MaSC in different mammalian species.

Therefore, the goal of the present study was to isolate and characterize MaSC from equine mammary gland tissues and more specifically, MaSC from nonlactating and lactating tissues to study potential differences between these 2 very important physiological mammary gland phases. To this end, previously described characterization experiments used in other species were optimized for identifying equine MaSC. Hereby, equine MaSC were enriched by culturing the cells under anchorage-independent condition, the so-called mammospheres. Next, equine MaSC were immunophenotypically characterized using cross-reacting antibodies (Abs) against stem cell markers and the cells were differentiated toward adult epithelial and myoepithelial cells using selective media. Moreover, colony forming unit (CFU) assays and mammosphere cycle assays were evaluated to see whether these assays are valuable additional in vitro systems to better characterize MaSC.

\section{Materials and Methods}

\section{Sample collection}

Inactive, nonlactating mammary gland tissues $(n=3)$ or active, lactating tissues $(n=3)$ from adult Warmblood slaughterhouse mares (8-12 years old) were collected by excising 2 parts of $5 \mathrm{~cm}^{2}$ of tissue next to the median line of the 2 mammary gland compartments. The samples did not show any macroscopic abnormalities and were transported to the laboratory on ice within $4 \mathrm{~h}$ after sampling in phosphate buffered saline (PBS) $1 \times$ (without calcium and magnesium) with $1 \%$ of penicillin/streptomycin/amfotericine $B$ (P/S/A, Sigma). A part of the sample was immediately fixed with $4 \%$ paraformaldehyde (PF) and hematoxylin-eosin stainings were performed on $8 \mu \mathrm{m}$ histological sections after paraffin embedding for histological examination.

\section{Collagenase digestion and mammosphere formation}

The isolation of equine mammosphere-initiating cells was based on the protocol of Dontu et al., with some modifications [31]. Upon arrival in the laboratory, mammary gland samples were dissociated mechanically with a sterile scalpel, followed by enzymatic digestion with $0.1 \%$ collagenase III (Worthington Biochemical Corporation) at $37^{\circ} \mathrm{C}$ for $60 \mathrm{~min}$. The cell suspension was subsequently filtered through a sterile 100 and $40 \mu \mathrm{m}$ filter to obtain a single cell suspension, and centrifuged at $400 \mathrm{~g}$ for $10 \mathrm{~min}$ at room temperature (RT). Cells were resuspended in PBS with $1 \% \mathrm{P} / \mathrm{S} / \mathrm{A}$, centrifuged at $260 \mathrm{~g}$ for $10 \mathrm{~min}$, and resuspended in MaSC medium, consisting of Dulbecco's modified Eagle's medium (DMEM)/F12 (50/50) supplemented with $10 \%$ of fetal bovine serum (FBS), 2\% B27 (all from Invitrogen), 1\% P/S/A (Sigma), $10 \mathrm{ng} / \mathrm{mL}$ basic-fibroblast growth factor (BioVision), and $10 \mathrm{ng} / \mathrm{mL}$ epidermal growth factor (Sigma). Approximately $5 \times 10^{5}$ cells were seeded on a 6-well tissue culture dish for $1 \mathrm{~h}$ to allow adherence of contaminating fibroblasts and this was repeated once more. The nonadherent cells were collected and seeded at approximately 20,000 cells $/ \mathrm{cm}^{2}$ on 6-well ultralow attachment plates (Corning, Elscolab). MaSC medium was refreshed twice a week by means of centrifugation of the mammospheres at $230 \mathrm{~g}$ for $6 \mathrm{~min}$. For further experiments, mammospheres were seeded on adhesive tissue culture dishes in MaSC medium, unless where indicated otherwise.

\section{Flow cytometry}

To characterize mammosphere cells immunophenotypically, the expression of several stem cell markers, previously used for the phenotypic characterization of MaSC in other species $[18,19,24,31-34]$, was evaluated by flow cytometry. Per series, $2 \times 10^{5}$ cells were used and labeled with the following primary Abs: mouse anti-human CD29-FITC $\mathrm{IgG}_{1}$ (Southern Biotech; clone TDM29, 1:10), rat anti-mouse CD44-APC $\operatorname{IgG}_{2 b}$ (BD; clone IM7, 1:20), rat anti-mouse CD49f $\operatorname{IgG}_{2 \mathrm{a}}$ (Novus Biologicals; clone GoH3, 1:10), and rabbit anti-human Ki67 IgG (Abcam; ab15580, 1:200). For the latter, cells were fixed with $4 \%$ PF for $10 \mathrm{~min}$ and subsequently permeabilized with $0.1 \%$ Triton $X$ for $2 \mathrm{~min}$, both at RT. Cells were incubated with the primary Abs for 15 min on ice in the dark and washed twice in washing buffer, consisting of DMEM with $1 \%$ bovine serum albumin. For CD49f and Ki67, secondary goat anti-rat Alexa ${ }^{488}$ - and goat antirabbit Alexa ${ }^{647}$-linked Abs (Invitrogen; 1:100), respectively, were used to identify positive cells after $15 \mathrm{~min}$ of incubation on ice in the dark. Finally, all cells were washed thrice in washing buffer and in addition, viability assessment with 
7-amino-actinomycin D (Sigma) was performed on the nonfixed cells. At least 10,000 cells were evaluated using a FACS Canto flow cytometer (Becton Dickinson Immunocytometry systems) equipped with a $488 \mathrm{~nm}$ solid state and a $633 \mathrm{~nm}$ HeNe laser, and these data were further analyzed with the FACS Diva software. All analyses were based on (i) autofluorescence and (ii) control cells incubated with isotypespecific IgGs, to establish the background signal. All isotypes were matched to the immunoglobulin subtype, conjugated to the same fluorochrome and used at the same protein concentration as the corresponding Abs.

\section{Differentiation experiments}

Differentiation of mammosphere cells toward the 2 major cell types present in the mammary gland, namely luminal epithelial and myoepithelial cells, was induced by culturing $2.5 \times 10^{3}$ cells $/ \mathrm{cm}^{2}$ in a 24-well plate in differentiation medium, consisting of DMEM/F12 (50/50), 10\% FBS, 2\% B27, $1 \% \mathrm{P} / \mathrm{S} / \mathrm{A}, 5 \mu \mathrm{g} / \mathrm{mL}$ insulin, $1 \mu \mathrm{g} / \mathrm{mL}$ hydrocortisone, and $1 \mu \mathrm{g} / \mathrm{mL}$ prolactin (Sigma), for 10 days. As a control, mammosphere cells were cultured in MaSC medium for 10 days. Media of the adherent cultures were refreshed every 3-4 days. Immunohistochemistry was performed to evaluate the expression of markers present on differentiated cells (see below).

For evaluation of 3-dimensional tubular structure formation, $5 \times 10^{3}$ cells $/ \mathrm{cm}^{2}$ were seeded in a 6 -well Synthemax plate (Corning, Elscolab) in differentiation medium supplemented with $50 \mathrm{pg} / \mathrm{mL}$ recombinant human transforming growth factor-beta3 (rhTGF- $\beta 3$, Sigma) and cultured for 10 days. Control MaSC were seeded on a normal tissue culture plate for 10 days as well. The formation of tubular/acinar structures was evaluated by light microscopic inspection of the wells.

For adipogenic differentiation, $2.1 \times 10^{4}$ cells $/ \mathrm{cm}^{2}$ were seeded in 4-well plates in MaSC medium and cultured upon $70 \%$ confluency. At that moment, adipogenic induction medium was added for 3 days, after which the medium was replaced with adipogenic maintenance medium for 1 more day. The adipogenic induction medium consisted of DMEM (Invitrogen) supplemented with $1 \mu \mathrm{M}$ dexamethasone, $0.5 \mathrm{mM}$ 3-isobutyl-1-methylxanthine, $10 \mu \mathrm{g} / \mathrm{mL}$ recombinant human-insulin, $0.2 \mathrm{mM}$ indomethacin, $15 \%$ rabbit serum, and $10 \mu \mathrm{L} / \mathrm{mL}$ antibiotic-antimycotic solution (all from Sigma) $[35,36]$. The adipogenic maintenance medium was identical but without dexamethasone, indomethacin, and 3isobutyl-1-methylxanthine. As a control, cells were seeded at a concentration of $2.1 \times 10^{4} / \mathrm{cm}^{2}$ in 4 -well plates in MaSC medium for 5 days. Adipogenesis was evaluated in all samples after 5 days of cultivation using Oil Red O stainings.

\section{Immunohistochemistry}

Cells were fixed for $10 \mathrm{~min}$ with $4 \% \mathrm{PF}$ and permeabilized for 2 min with $0.1 \%$ Triton $X$, both at RT. Cells were then incubated with $0.03 \%$ hydrogen peroxide for $5 \mathrm{~min}$ at RT and after washing with PBS, incubated for $2 \mathrm{~h}$ at RT with the following primary mouse $\mathrm{IgG}_{1}$ monoclonal Abs: anti-human cytokeratin (CK)18 (Abcam; clone C-04, 1:30), anti-human PanCK (Dako; clone, AE1/AE3, 1:50), and anti-porcine vimentin (Thermo Scientific; clone V9, 1:100); the mouse antihuman smooth muscle actin (SMA) IgG2a Ab (Dako; clone
$1 \mathrm{~A} 4,1: 200)$ and the rabbit anti-human $\mathrm{IgG}$ Ab casein kinase $2 \beta$ (Abcam; clone EP1995Y, 1:50). All antibodies were used at the concentrations indicated by the manufacturer. After washing with PBS, secondary ready to use goat anti-mouse and anti-rabbit peroxidase-linked antibodies (Dako) were added and incubated for $30 \mathrm{~min}$ at RT. Finally, 3,3'-diaminobenzidine was added for 2-10 min and a counter staining with hematoxylin was performed to visualize the surrounding cells. As controls, identical stainings were performed on undifferentiated mammosphere cells and background staining was assessed by using the proper isotype-specific IgGs. All isotypes were matched to the immunoglobulin subtype and used at the same protein concentration as the corresponding Abs.

\section{Mammosphere cycle assay}

First cycle mammospheres, which were developed from inactive, nonlactating- and lactating mammary gland tissuederived cells on ultralow attachment plates (as described above), were counted at days 4,7 , and 11 postseeding. In addition, 10 mammospheres were photographed and average mammosphere areas were determined using Image $J$ software (http://rsb.info.nih.gov/ij/). At day 11 postseeding, all mammospheres were collected and plated on adhesive tissue culture dishes in MaSC medium. Upon $80 \%$ confluency, the adherent cells were trypsinized with $0.25 \%$ trypsin-ethylenediaminetetraacetic acid and seeded at a very low density of 4,000 cells $/ \mathrm{cm}^{2}$ in a 6-well ultralow attachment plate to initiate a second mammosphere cycle. These second cycle mammospheres were counted and evaluated exactly as described for the first cycle mammospheres. To calculate the mammosphere forming efficiency (MFE), the number of mammospheres was divided by the original number of single cells seeded and expressed as a percentage, exactly as previously described $[37,38]$.

\section{CFU assay}

Approximately 1 mammosphere cell was seeded per $\mathrm{cm}^{2}$ of a 6-well plate and fixed 7 days later with $90 \%$ ethanol for $10 \mathrm{~min}$ at $-20^{\circ} \mathrm{C}$. Crystal violet stainings were performed to visualize CFUs macroscopically and the total number of CFUs per 6-well were counted. CFU assays were done in duplicate for 3 independent experiments.

\section{Statistical analysis}

Student's $t$-test for paired data was used to test for statistically significant differences in mammosphere numbers, areas, and CFU assays between MaSC from nonlactatingand lactating mammary gland tissue. Data given are the mean of 3 independent experiments and the bars show standard deviations.

\section{Results}

\section{Histological evaluation of the mammary gland tissue samples}

The physiological activity status of all mammary gland tissue samples used was confirmed by histology. Hereby, it was observed that the inactive, nonlactating mammary 
FIG. 1. Hematoxylin-eosin staining of equine inactive, nonlactating (A) and lactating (B) mammary gland tissues. Small alveoli with a narrow lumen lined by small cuboidal cells were noticed in inactive mammary gland tissues, whereas large and dilated alveoli containing milk secretion (arrow) were visible in lactating mammary gland tissues. Bars represent $500 \mu \mathrm{m}$ (a) and $50 \mu \mathrm{m}$ (b).
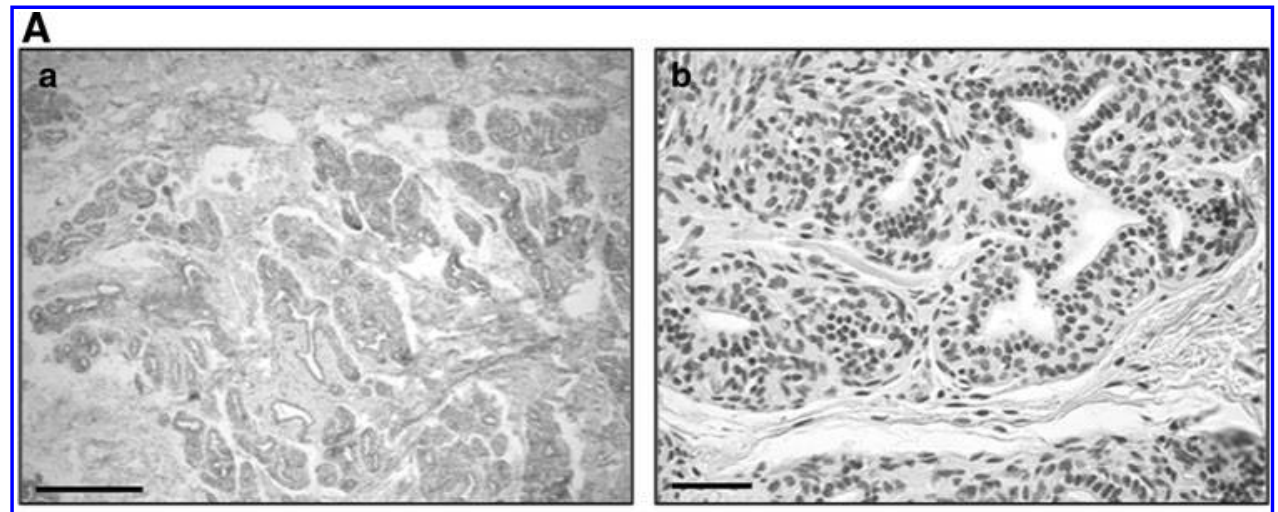

B

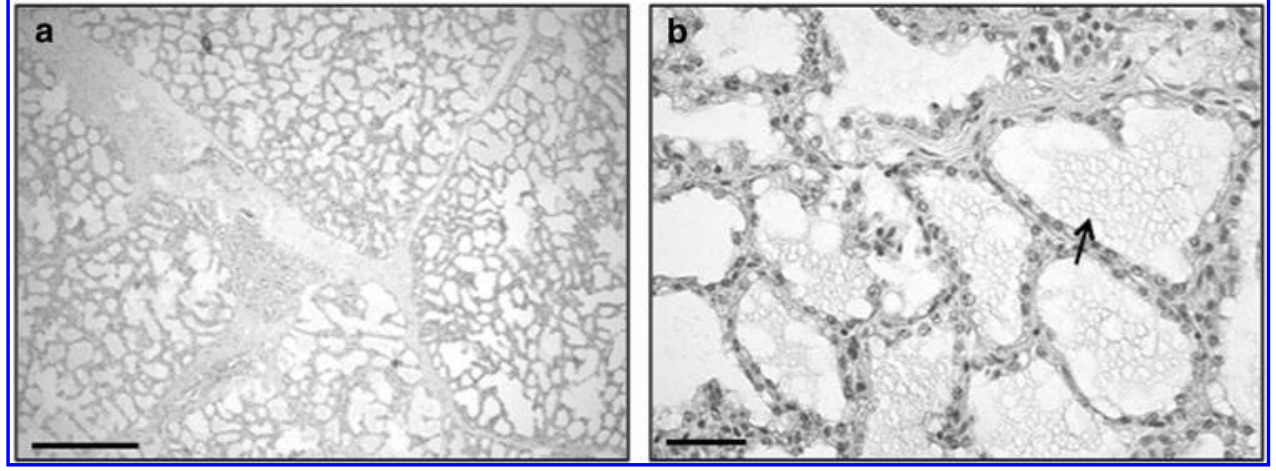

gland tissues consisted of small alveoli with a narrow lumen lined by small cuboidal cells (Fig. 1A), whereas the lactating mammary gland tissues consisted of large and dilated alveoli containing milk secretion in their lumina (Fig. 1B).

\section{Equine mammary gland tissue-derived cells are capable of mammosphere formation}

Mammosphere formation is a frequently used in vitro cultivation system that allows the propagation of MaSC by
FIG. 2. The mammosphere cycle assay. After mammosphere formation on ultralow attachment plates (first mammosphere cycle, I), mammosphere-derived cells are cultured on tissue culture dishes (II). Upon confluency, adherent cells are cultured on ultralow attachment plates (second mammosphere cycle, III), and subsequently cultured on tissue culture dishes (IV). Representative pictures of mammospheres and adherent mammosphere-derived cells are shown. Bars represent $50 \mu \mathrm{m}$. MaSC, mammary stem/progenitor cells.

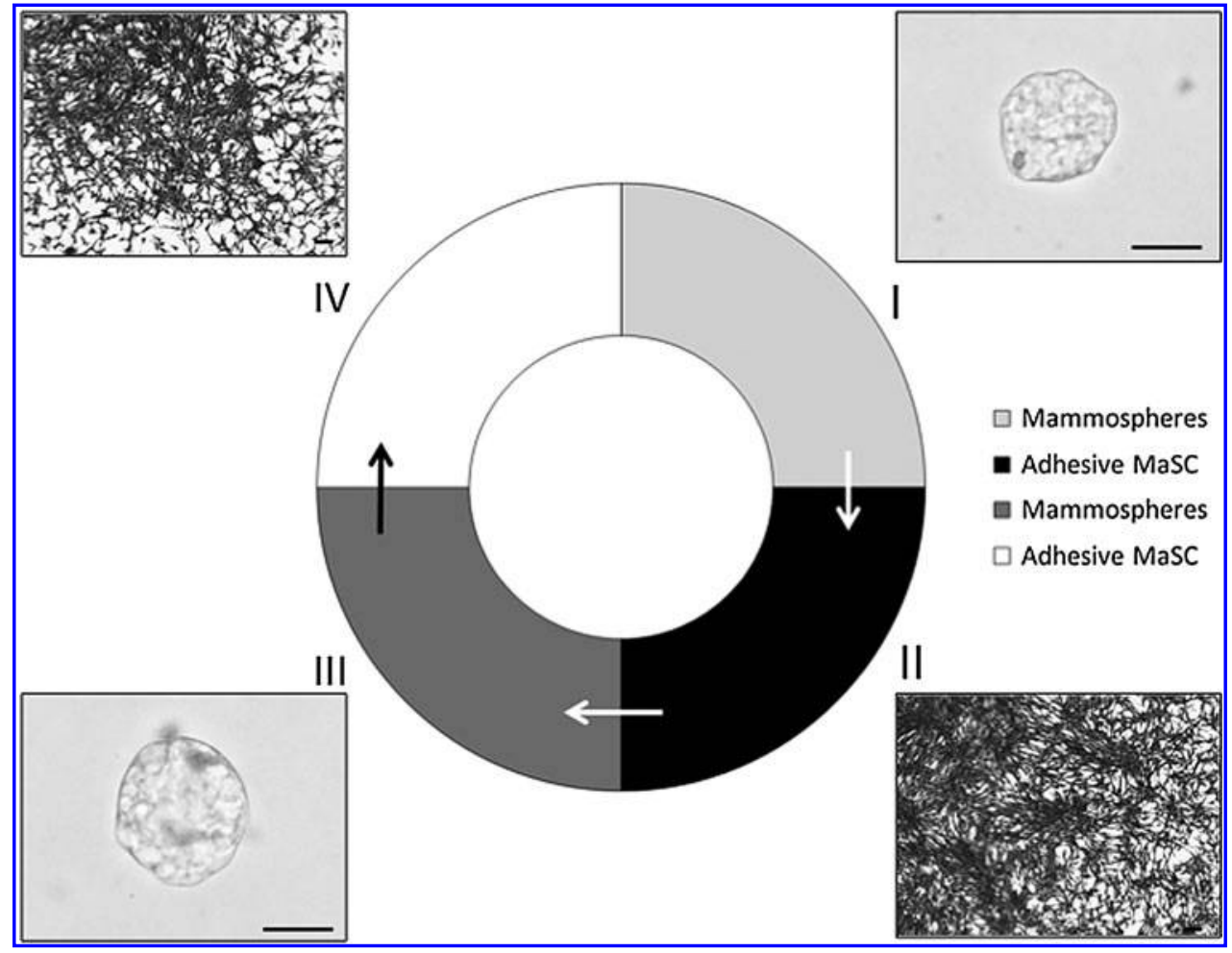


culturing enzymatically digested mammary gland cells on ultralow attachment plates to prevent adhesion [31]. The formation of mammospheres, typically consisting of nonadherent spherical clusters of cells, could be observed in all cultures as early as 4 days postseeding. Since mammospheres consist of a mixture of stem cells, their progeny, and nonstem progenitor cells [34], the observed equine mammospheres thus indicate that at least some mammary epithelial cells with stem cell characteristics, or MaSC, could be obtained with this technique. In Fig. 2I and III, representative pictures of equine mammospheres are presented. These mammospheres could, upon trypsinization to obtain single cells again, be passaged on ultralow attachment plates up to passage (P) 6. From P6 onward, the vitality of the cells rapidly declined and by $\mathrm{P} 8$, no more mammospheres could be observed.

\section{Equine mammosphere cells are positive for stem cell markers}

Next, the mammosphere-derived cells were immunophenotypically characterized by flow cytometry and virtually all cells were positive for the stem cell surface markers CD29, CD44, CD49f, and the proliferation marker Ki67,

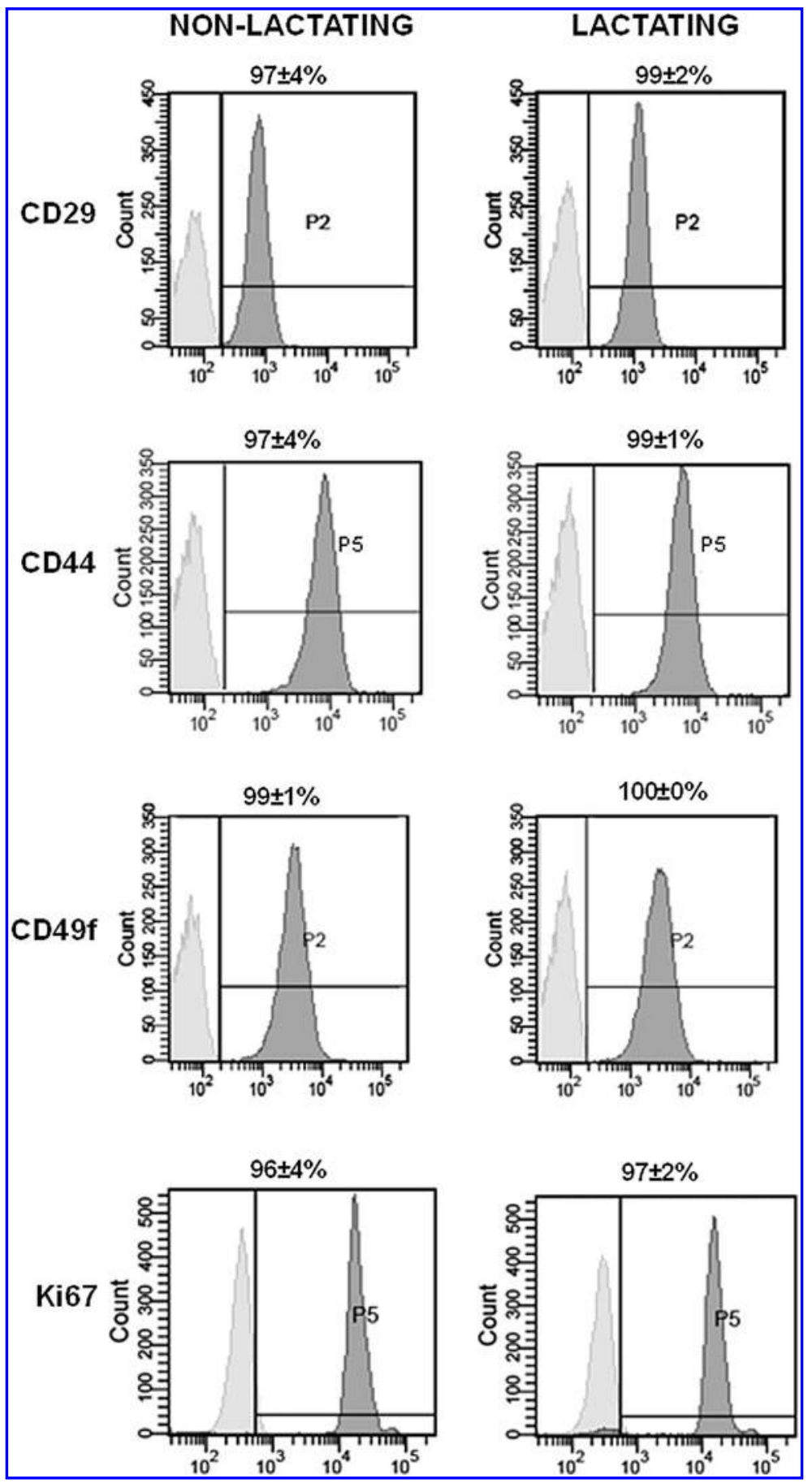

FIG. 3. Immunophenotypic characterization of mammosphere cells from equine inactive, nonlactating- and lactating mammary glands. Flow cytometry was performed with a set of 4 markers: CD29, CD44, CD49f, and Ki67. Histograms show relative numbers of cells versus mean fluorescence intensity with the isotype control staining (light gray) and marker antibody staining (dark gray). Data represent the mean percentage of 3 experiments \pm standard deviations. 
regardless of the activity status of the mammary gland (Fig. 3). No fluorescence signal was obtained with the appropriate isotype controls (Fig. 3).

\section{Equine mammosphere cells can differentiate into luminal epithelial and myoepithelial cells and form 3-dimensional tubular structures}

The mammosphere-derived cells were also subjected to a functional characterization by culturing the cells in selective media that was supplemented with insulin, hydrocortisone and prolactin. After 10 days of culture, the structural organization of the cells changed from a monolayer (control cells) toward an acinar formation (differentiated cells; Fig. 4). The cells in these structures were immunohistochemically characterized as luminal epithelial and myoepithelial cells by using markers that were previously described for human and bovine MaSC differentiation studies [24,25,31,39-41]. Luminal epithelial cells showed a strong cytoplasmic staining for CK18 and a weak positive signal for the PanCK marker (Fig. 4). For casein kinase $2 \beta$, both a nuclear and cytoplasmic immunolabeling was observed in these cells. A positive immunolabeling was not observed in mammosphere cells that had been cultured in normal MaSC medium (control cells), with the exception of casein kinase $2 \beta$, which showed a cytoplasmatic staining (Fig. 4). To characterize myoepithelial cells, an Ab against SMA was used and cells positive for this marker were found in the differentiated cell cultures, but not in the control cultures (Fig. 4). Lastly, a staining for vimentin was also included and positive cells were found in the control cells and in the acinar differentiated cells (Fig. 4). No signal was detected in the differentiated cell cultures when relevant isotypic controls were used for staining (Fig. 4).
FIG. 4. Differentiation of mammosphere cells into luminal epithelial and myoepithelial cells. Immunohistochemistry was performed on control and differentiated cells using CK 18, PanCK, casein kinase 2 $\beta$, SMA, and vimentin markers. Relevant isotype controls were also included. Arrows indicate positive stainings and bars represent $50 \mu \mathrm{m}$. CK, cytokeratin; SMA, smooth muscle actin.

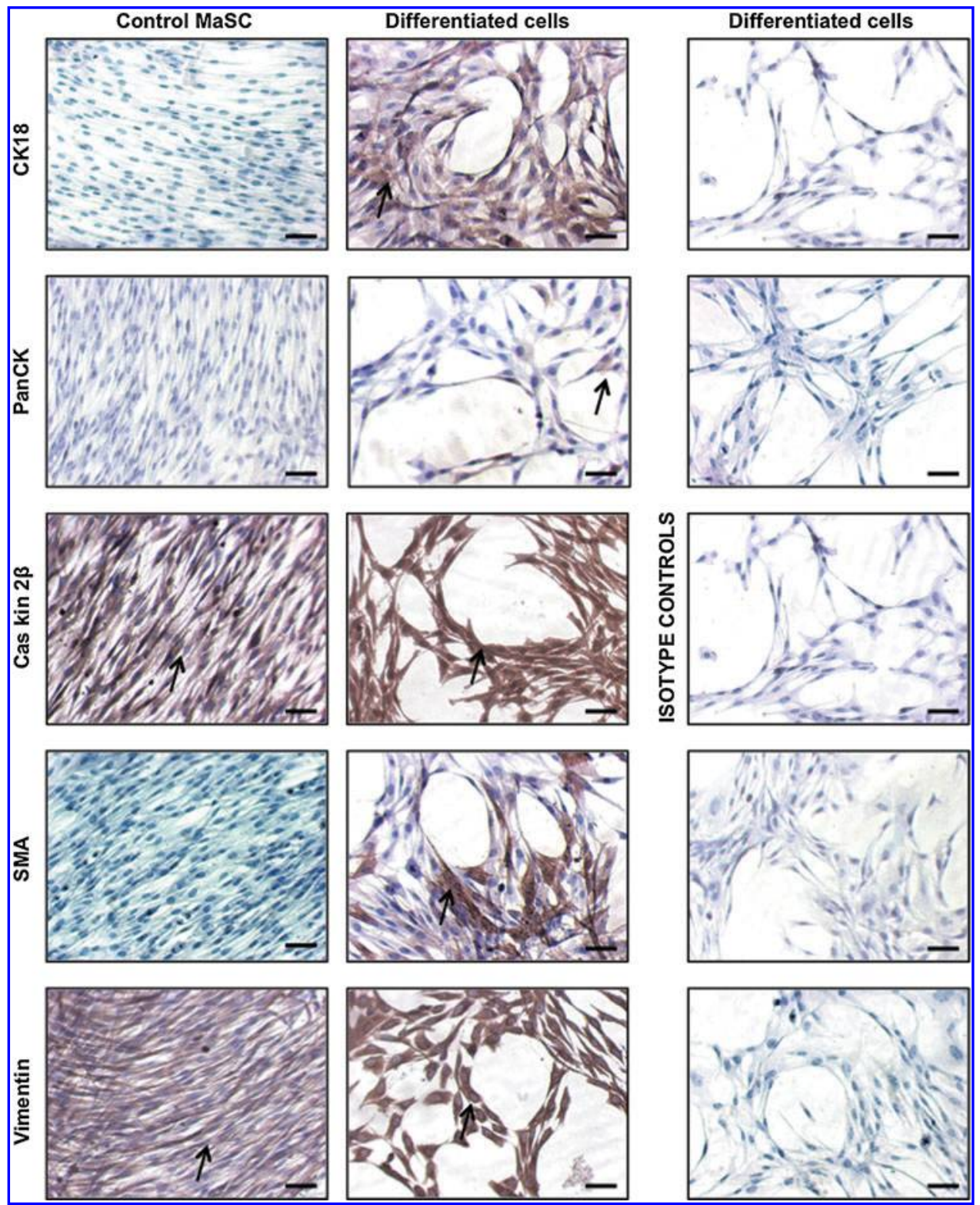


When culturing the mammosphere cells on Synthemax plates in the differentiation medium supplemented with rhTGF- $\beta 3$, tubular, acinar, and alveolar structures could be noticed in the cultures by light microscopy within 10 days of culture (Fig. 5). Control cells were cultivated on normal tissue culture plates (Fig. 5).

\section{Equine mammosphere cells can differentiate into adipocytes}

To assess the stem cells' potency, differentiation toward cell types of other germ layers can be performed [42]. Here, mammosphere-derived cells were cultured in a selective medium that is typically used to differentiate adult mesenchymal stem cells (MSC), originating from the mesodermal germ layer, into adipocytes [35]. Interestingly, within 5 days of culturing in such medium, the mammosphere cells morphologically changed from spindle-shaped to round cells and the production of small intracellular granules could be microscopically noticed in the cultures (Fig. 6). Subsequent Oil Red O stainings confirmed the presence of lipids in these cells (Fig. 6), indicating that mammosphere cells, which originate from the epidermal germ layer, are capable of differentiating into cell types of the mesodermal germ layer. Controls of nondifferentiated cells subjected to the same detection method maintained their spindle-shaped morphology with the formation of a monolayer and stained negative (Fig. 6).

\section{Equine mammosphere cells from nonlactating- and lactating mammary gland tissues exhibit similar clonogenic expansion capacities}

To monitor and compare the clonogenic expansion of mammosphere cells from inactive, nonlactating versus lactating mammary gland tissues, CFU assays were performed. To this end, a limited number of cells was seeded at clonal density on a large surface $\left(1 \mathrm{cell} / \mathrm{cm}^{2}\right.$ on a 6-well plate) and cultured for around a week. After cultivation, 2 different colony stages could be observed. One stage consisted of "dispersed" CFUs, identified by a spotted, vague macroscopic morphology and rather distant cells microscopically, whereas the other stage consisted of "fingerprint" CFUs, which were darker and more packed at macroscopic examination and with a microscopic fingerprint pattern. Overall, more dispersed colonies were observed compared to fingerprint CFUs (Fig. 7). No differences between cells from inactive, nonlactating mammary gland tissues and cells from lactating mammary gland tissues were noted (Fig. 7).

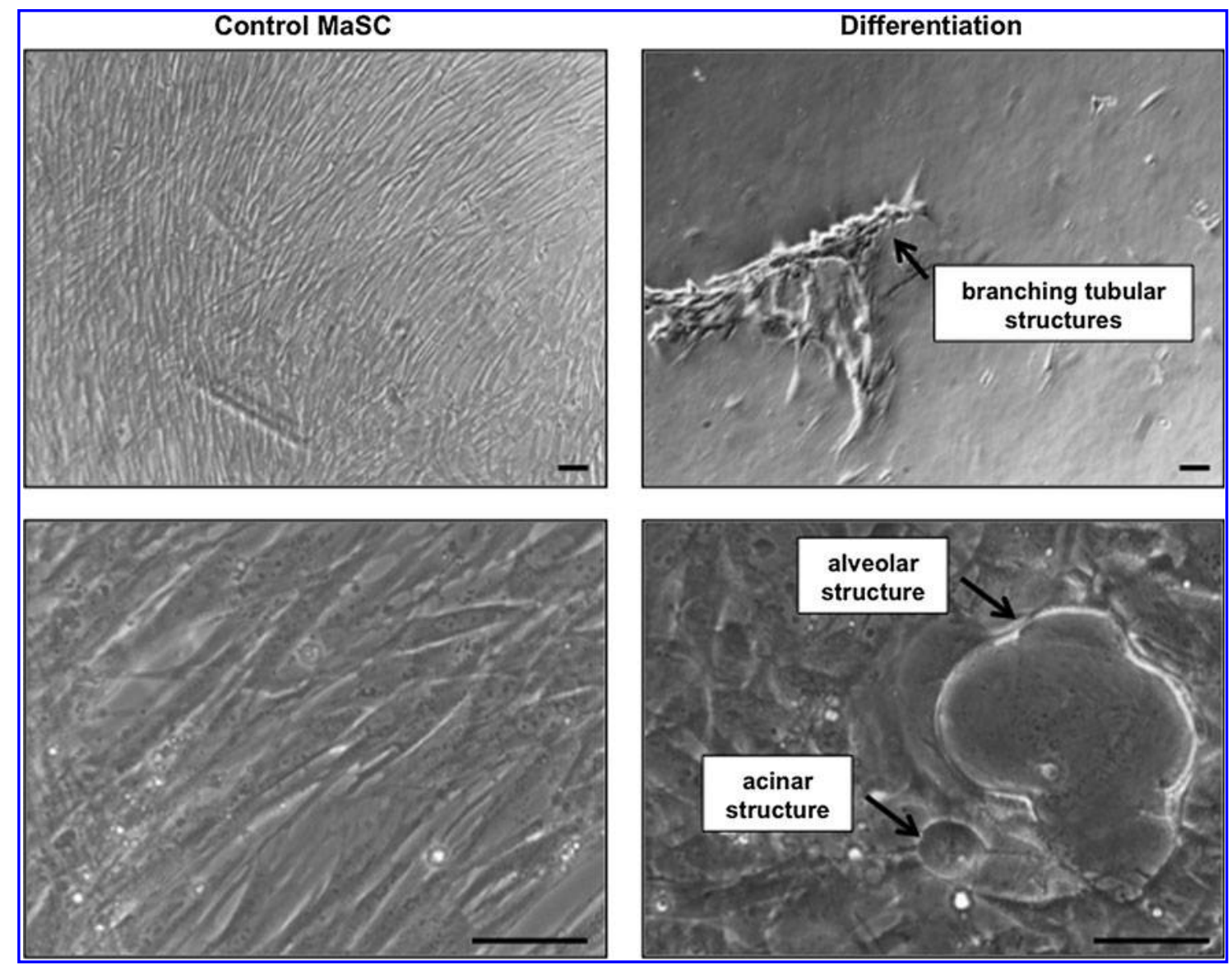

FIG. 5. Three-dimensional tubular structure formation. Mammosphere-derived cells were cultured on Synthemax plates and acino-tubular structures were analyzed by light microscopy at different magnifications. Control cells were seeded on normal culture plates. Bars represent $50 \mu \mathrm{m}$. 


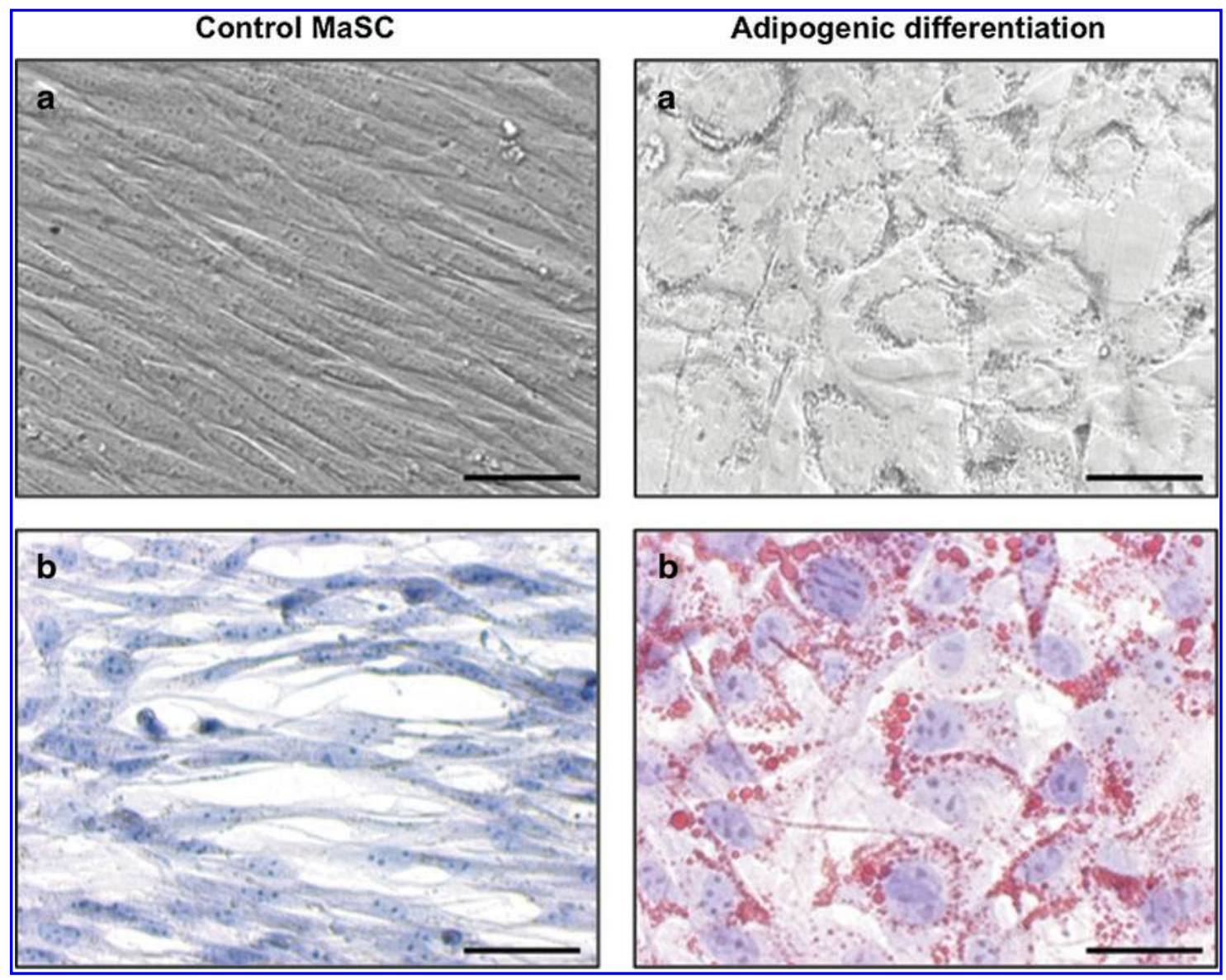

FIG. 6. Adipogenic differentiation. Mammosphere-derived cells were cultured in adipogenic induction- and maintenance medium and analyzed by light microscopy (a) and Oil Red O stainings (b). Bars represent $50 \mu \mathrm{m}$.

\section{Cells from lactating mammary gland tissues generate more and larger mammospheres than cells from inactive, nonlactating tissues}

Mammosphere cycle assays, as described in the Material and Methods section and Fig. 2, were initiated to evaluate whether this assay could be a valuable additional in vitro system to better characterize MaSC. Hereby, it was found that the number of mammospheres derived from lactating mammary gland cells was higher than those from inactive, nonlactating tissues, a finding significant for all time points during the first cycle of the mammosphere assay (Fig. 8A). In addition, the MFE during the first mammosphere cycle varied between $0.8 \%$ and $1.5 \%$ for cells isolated from nonlactating versus $1.9 \%-3.2 \%$ for cells isolated from lactating mammary glands (Fig. 8A). During the first mammosphere cycle, a 2-fold increase in the number of mammospheres was noted between 4 and 7 days of culture, irrespective of the tissue type (Fig. 8A). This finding is in good agreement with another study, where a 2-fold increase was also noted in the number of mammospheres from freshly isolated Balb/c mammary epithelial cells cultured for 4 days and for 7 days [37]. Moreover, when evaluating the size of the generated mammospheres, it was found that the first cycle mammospheres were significantly larger at day 4 for cells originating from lactating tissues $(P=0.044$; Fig. $8 \mathrm{~B})$. At days 7 and 11, this difference was still noticeable, but no longer statistically significant (Fig. 8B). During the second cycle mammosphere assay, significant differences in number, MFE or size of mammospheres from nonlactating- and lactating mammary gland tissues were no longer apparent (Fig. 8A, B).

\section{Discussion}

Much of the available data on mammary gland development comes from rodents [43], although variation in mammary growth and function exist between mammals, especially with regard to the endocrine control of these processes [44,45]. Because (i) MaSC are proposed as the driving forces behind mammary growth and function and (ii) variation exists between mammalian species with regard to physiological and pathological functioning of this organ, we believe that studying MaSC from different species is of great comparative interest.

In the present study, we aimed to isolate and characterize MaSC from the mammary gland of horses. Briefly, equine mammosphere-derived cells were immunophenotypically characterized by using stem cell markers CD29, CD44, CD49f, and the proliferation marker Ki67. The latter was included to give an indication of the self-renewal rate of the cells, since this nuclear protein is only expressed during the late growth $(\mathrm{G})_{1}$-phase and the synthesis (S)-, mitosis (M)-, and $\mathrm{G}_{2}$-phase of the cell cycle [46]. Moreover, a successful differentiation toward luminal (alveolar and ductal) 


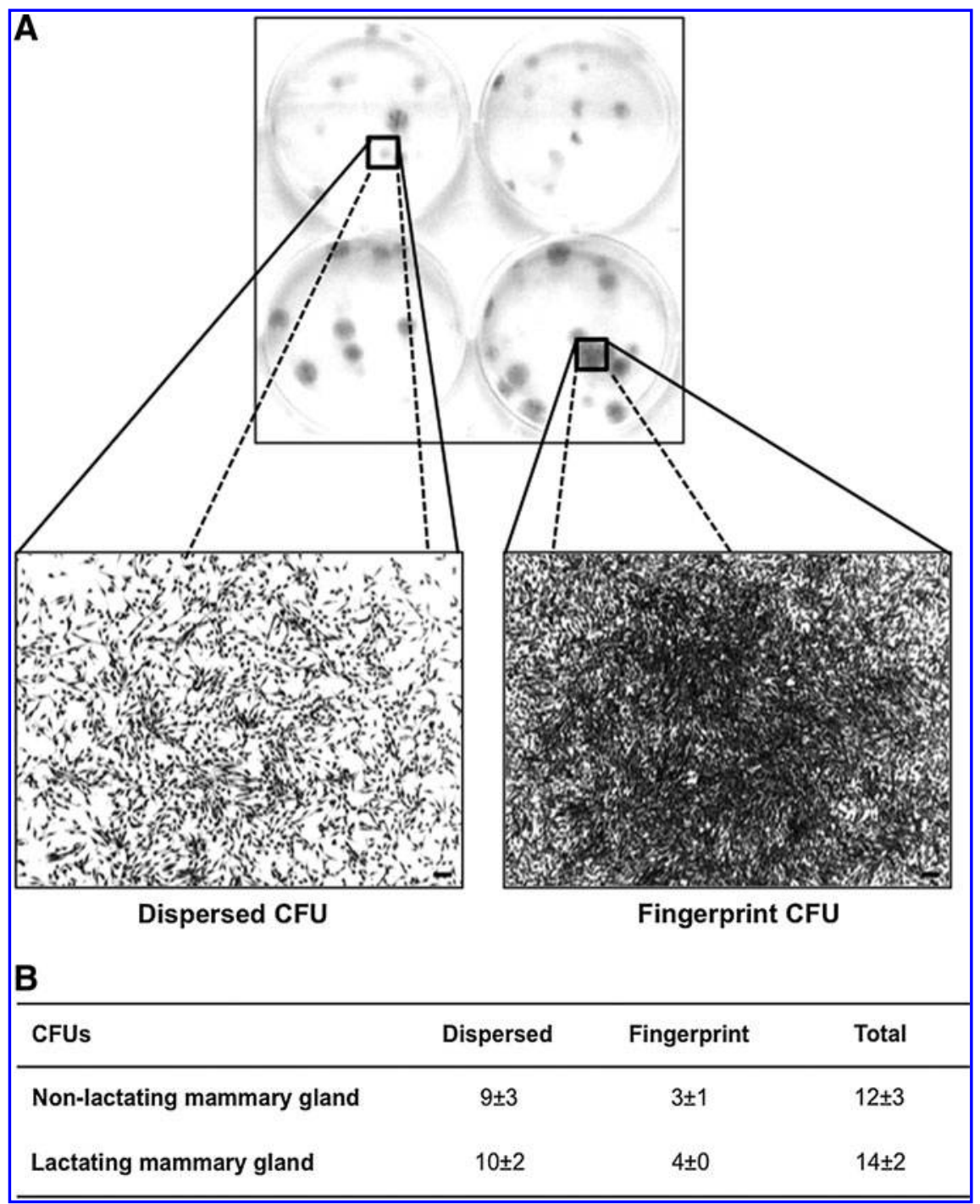

FIG. 7. CFU assays of mammosphere cells derived from inactive, nonlactating- and lactating mammary gland tissues. Macroscopic- and microscopic images of dispersed and fingerprint CFUs after crystal violet staining (A). Bars represent $100 \mu \mathrm{m}$. Numbers of CFUs were counted per 6-well and data represent the mean percentage of 3 experiments \pm standard deviations (B). CFU, colony forming unit. epithelial and myoepithelial cells, the 2 major adult epithelial mammary gland cell types, was achieved. Luminal ductal epithelial cells, at least in mice, ramify through the fat pad before puberty and further proliferate under the influence of hormones in early pregnancy/gestation [47]. During lactation, the myoepithelial cells will contract under the stimulation of oxytocin, thereby ejecting the milk from the luminal alveolar epithelial cells $[31,48]$. For the latter, we found that after differentiating our equine mammosphere cells, which contained at least some mammary epithelial cells with stem cell characteristics, into adult luminal epithelial cells, these cells became positive for CK18, whereas no expression was found on the undifferentiated control cells. This is in accordance with a human MaSC study [31] and in contrast with a murine study, where it was found that undifferentiated MaSC were CK18 positive [49]. In several studies it was found that murine MaSC were also positive for CK14 [49,50], however, we were unable to evaluate the expression of this $\mathrm{CK}$ on our equine mammosphere cells and their differentiated progeny, due to a lack of cross-reactivity of several CK14 antibodies tested (data not shown). In the present study, the differentiation of mammosphere cells toward both luminal and myoepithelial cells was achieved using 1 culture medium. This is in contrast to a study on bovine MaSC where 2 different selective media were used [24], but in line with what has been previously reported for the differentiation of canine [18] and human MaSC [51]. Lastly, but interestingly, the equine mammosphere cells were capable of differentiating into adipocytes when cultured in adipocyteinducing selective media [35]. Several independent studies report the differentiation of stem cells into cell types of another germ layer [52,53]. Here, we studied mammosphere cells, originating from the ectoderm, and showed that they were capable of differentiating into a cell type from the mesoderm, namely adipocytes. Since adipogenic transdifferentiation of human amnion and chicken oviduct adult epithelial cells has been reported [54,55], the adipogenesis of epithelial mammosphere cells is not an unusual phenomenon.

It has to be noted, however, that some of the markers described above, including CD29, CD44, and CD49f, are not MaSC-specific but are also expressed on other stem cells such as MSC $[35,56,57]$. So, to ensure that the adipogenesis we observed was caused by epithelial cells with stem cell 


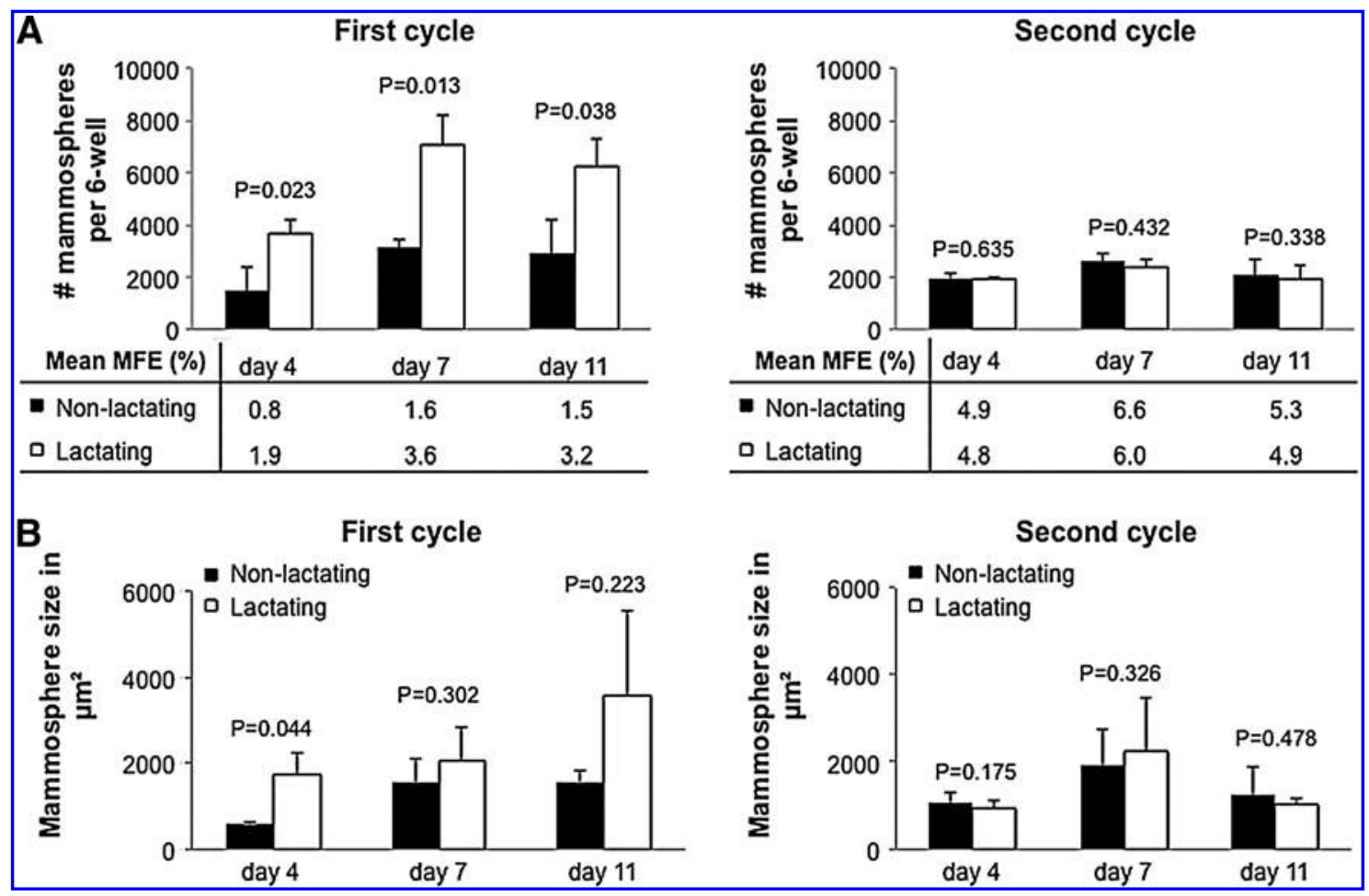

FIG. 8. Mammosphere cycle assays of nonlactating- and lactating equine mammary gland tissues. Numbers of mammospheres were counted per 6-well (A) and mammosphere sizes were calculated in $\mu \mathrm{m}^{2}$ (B). To calculate the MFE, the number of mammospheres was divided by the original number of single cells seeded and expressed as a percentage. Calculations were made at 3 time points postseeding and data represent the mean of 3 experiments \pm standard deviations. MFE, mammosphere forming efficiency.

characteristics, or MaSC, and not merely an effect of contaminating MSC, we included the epithelial-specific marker casein kinase $2 \beta$ [58]. Flowcytometric analysis revealed that the equine mammosphere-derived cells were positive for this marker, in contrast to equine MSC, which were casein kinase $2 \beta$-negative (data not shown).

The lack of in vivo functional assays has been pointed out as a vital drawback of current MaSC research [59]. Indeed, because the use of a cleared fat pad model is not really feasible in horses, we aimed to evaluate additional in vitro assays to better characterize equine MaSC. In our present study, we evaluated CFU assays and mammosphere cycle assays in equine cells from nonlactating versus lactating mammary glands. First, we assessed the clonogenic potential of mammosphere-derived cells derived from both physiological mammary gland stadia with the CFU assays and virtually identical results were obtained, indicating that the in vitro clonogenic potential of MaSC from lactating versus nonlactating mammary gland tissue is similar. Interestingly, 2 different colony morphologies were observed in the CFU assay at 7 days of culture (end of the experiments). The presence of different colony types has been previously described for human keratinocytes and other cell types: (i) holoclones: large colonies with lots of small cells that were shown to have the greatest reproductive capacity, (ii) paraclones: smaller colonies with large, flattened cells that have a short replicative lifespan, and (iii) meroclones: a transitional stage between the holo- and paraclone that contains a mixture of cells with different growth potential [60]. Based on these descriptions, we would like to hypothesize that the fingerprint colonies observed in the present study might represent holoclones, whereas the dispersed colonies resemble paraclones. Future experiments of subculturing the colony types observed in the present study by transferring them to indicator dishes, as described in the article of Barrandon and Green [61], will give more information on their growth potential and might prove an elegant method to determine the progenitor cell hierarchy in a given mammary gland sample under different (patho)physiological conditions. The existence of a progenitor cell hierarchy in the mammary gland has already been extensively studied in the human and murine mammary gland $[31,34,62,63]$, but information on other mammal species remains limited to date.

Second, the number and the size of the mammospheres was determined in both sample types using the in vitro mammosphere cycle assay. Hereby, the number of mammospheres formed upon serial passage reflects self-renewal of primitive MaSC, whereas the mammospheres' size is a reflection of progenitor cell proliferation [31]. Interestingly, we found significantly more and larger mammospheres when cells were derived from lactating mammary glands compared with inactive, nonlactating mammary gland tissues, at least in the first mammosphere cycle. Also, during the first cycle of the mammosphere cycle assay, a 2-fold difference was found between the MFE of the inactive, nonlactating (on average $1.3 \%$ ) versus the lactating (on average $2.9 \%$ ) equine mammary glands. A difference in MFE has been previously reported between epithelial cells from normal human breast tissue and breast tissue with ductal carcinoma in situ (DCIS), with the latter showing a 
significantly greater MFE [38]. The authors hereby suggested that a greater MFE, as seen in the DCIS samples, translates into the presence of a greater number of stem or progenitor cells [38]. So, based on the MFE data from our present study, the equine mammary gland appears to harbor a higher number of MaSC during lactation compared with the inactive, resting state. Moreover, the significantly larger mammospheres indicate that MaSC possess a higher progenitor cell proliferation rate during lactation. This is in line with what has previously been reported regarding lactation physiology in horses, where it was found that during lactation, cell divisions increase in line with milk production $[29,30]$. This physiological process during lactation is most likely represented by MaSC, since we demonstrated that MaSC from lactating tissues are higher in number and show higher proliferation capacities. On the other hand, it has been proposed in rodents that murine MaSC are relatively quiescent during lactation $[64,65]$, which is in contrast to the increased proliferation rates, depicted by the larger mammosphere sizes, which were observed with the equine lactating mammary gland tissues. Hence, these results emphasize once more the importance of studying mammary gland physiology in general, and MaSC biology in specific, in different mammalian species.

For the second cycle of the mammosphere assay, spheres from the first cycle were collected, plated for $1 \mathrm{P}$ on an adherent plate and after trypsinization, replated at 4,000 cells/ $\mathrm{cm}^{2}$. Hereby, it was observed that mammospheres derived from mammary gland tissue had the capacity to form new generations of mammospheres in the second mammosphere cycle, with a similar regeneration capacity (MFE of $5.6 \%$ vs. $5.2 \%$ on average) between the 2 tissue samples (nonlactating vs. lactating, respectively). This is in contrast to the study with the normal human breast and DCIS tissues. There, they found that DCIS mammospheres were capable of regenerating mammospheres at a significantly higher regeneration ratio compared with normal breast mammospheres [38]. A potential explanation for the lack of any difference in the second mammosphere cycle, observed in the present study, could be due to the fact that for this second cycle, mammospherederived cell populations were used after $1 \mathrm{P}$ on an adherent plate. It would be interesting to see if reseeding mammospheres as single cells directly under nonadherent conditions, would result in a difference between nonlactating and lactating tissues. Interestingly, the lack of any difference in the second mammosphere cycle reflects the lack of any difference observed in the CFU assays. For the latter, 1 mammospherederived cell obtained from an adherent culture was seeded per $\mathrm{cm}^{2}$ of a 6-well plate. It would be interesting to see whether mammosphere populations where a difference in CFUs is observed, will also display the same difference in the second mammosphere cycle assay. Future work will therefore focus on further optimizing and validating these assays to determine the number and MFE of MaSC present in the mammary gland at certain (patho)physiological stadia such as mastitis and mammary tumor formation not only in horses, but also in other mammalian species.

In conclusion, this study is the first to report on the isolation and characterization of equine MaSC. Further, we describe the valuable use of additional in vitro assays to compare mammospheres and mammosphere-derived cells in the mammary gland at different physiological stages.

\section{Acknowledgments}

This study was supported by a grant to J.H.S. from the agency for innovation by science and technology (IWT). G.V.de W. is a postdoctoral fellow of the FWO Flanders. The authors wish to thank Sarah Loomans and Cynthia de Vries from the Department of Pathology, Bacteriology, and Poultry Diseases for their technical assistance.

\section{Author Disclosure Statement}

The authors declare that they have no competing interests.

\section{References}

1. Motyl T, JB Bierla, M Kozlowski, M Gajewska, B Gajkowska and M Koronkiewicz. (2011). Identification, quantification and transcriptional profile of potential stem cells in bovine mammary gland. Livest Sci 136:136-149.

2. Tiede B and YB Kang. (2011). From milk to malignancy: the role of mammary stem cells in development, pregnancy and breast cancer. Cell Res 21:245-257.

3. Lewis MT. (2000). Homeobox genes in mammary gland development and neoplasia. Breast Cancer Res 2:158-169.

4. Kass L, JT Erler, M Dembo and VM Weaver. (2007). Mammary epithelial cell: influence of extracellular matrix composition and organization during development and tumorigenesis. Int J Biochem Cell Biol 39:1987-1994.

5. Shackleton M, F Vaillant, KJ Simpson, J Stingl, GK Smyth, ML Asselin-Labat, L Wu, GJ Lindeman and JE Visvader. (2006). Generation of a functional mammary gland from a single stem cell. Nature 439:84-88.

6. Soule HD and CM McGrath. (1986). A simplified method for passage and long-term growth of human mammary epithelial cells. In Vitro Cell Dev Biol 22:6-12.

7. Petersen OW, L Ronnov-Jessen, AR Howlett and MJ Bissell. (1992). Interaction with basement membrane serves to rapidly distinguish growth and differentiation pattern of normal and malignant human breast epithelial cells. Proc Natl Acad Sci U S A 89:9064-9068.

8. Stingl J, CJ Eaves, I Zandieh and JT Emerman. (2001). Characterization of bipotent mammary epithelial progenitor cells in normal adult human breast tissue. Breast Cancer Res Treat 67:93-109.

9. Bruno RD and GH Smith. (2011). Functional characterization of stem cell activity in the mouse mammary gland. Stem Cell Rev 7:238-247.

10. Visvader JE and GH Smith. (2011). Murine mammary epithelial stem cells: discovery, function, and current status. Cold Spring Harb Perspect Biol 3:a004879.

11. Young LJ, D Medina, KB DeOme and CW Daniel. (1971). The influence of host and tissue age on life span and growth rate of serially transplanted mouse mammary gland. Exp Gerontol 6:49-56.

12. Molofsky AV, R Pardal and SJ Morrison. (2004). Diverse mechanisms regulate stem cell self-renewal. Curr Opin Cell Biol 16:700-707.

13. Reya T, SJ Morrison, MF Clarke and IL Weissman. (2001). Stem cells, cancer, and cancer stem cells. Nature 414:105-111.

14. Cardiff RD, HA Bern, LJ Faulkin, CW Daniel, GH Smith, LJ Young, D Medina, MB Gardner, SR Wellings, et al. (2002). Contributions of mouse biology to breast cancer research. Comp Med 52:12-31.

15. Young LJ. (2008). Mus tales: a hands-on view. J Mammary Gland Biol Neoplasia 13:343-349. 
16. Munson L and A Moresco. (2007). Comparative pathology of mammary gland cancers in domestic and wild animals. Breast Dis 28:7-21.

17. Knight $\mathrm{CH}$ and A Sorensen. (2001). Windows in early mammary development: critical or not? Reproduction 122: 337-345.

18. Cocola C, P Anastasi, S Astigiano, E Piscitelli, P Pelucchi, L Vilardo, G Bertoli, M Beccaglia, MC Veronesi, et al. (2009). Isolation of canine mammary cells with stem cell properties and tumour-initiating potential. Reprod Domest Anim 44 Suppl 2:214-217.

19. Michishita M, R Akiyoshi, H Yoshimura, T Katsumoto, H Ichikawa, K Ohkusu-Tsukada, T Nakagawa, N Sasaki and K Takahashi. (2011). Characterization of spheres derived from canine mammary gland adenocarcinoma cell lines. $\underline{\text { Res Vet }}$ Sci 91:254-260.

20. Hellmen E, M Moller, MA Blankenstein, L Andersson and B Westermark. (2000). Expression of different phenotypes in cell lines from canine mammary spindle-cell tumours and osteosarcomas indicating a pluripotent mammary stem cell origin. Breast Cancer Res Treat 61:197-210.

21. Kumaraguruparan R, D Karunagaran, C Balachandran, BM Manohar and S Nagini. (2006). Of humans and canines: a comparative evaluation of heat shock and apoptosis-associated proteins in mammary tumors. Clin Chim Acta 365:168-176.

22. Kumaraguruparan R, D Prathiba and S Nagini. (2006). Of humans and canines: immunohistochemical analysis of PCNA, Bcl-2, p53, cytokeratin and ER in mammary tumours. Res Vet Sci 81:218-224.

23. Uva P, L Aurisicchio, J Watters, A Loboda, A Kulkarni, J Castle, F Palombo, V Viti, G Mesiti, et al. (2009). Comparative expression pathway analysis of human and canine mammary tumors. BMC Genomics 10:135.

24. Li JX, Y Zhang, LB Ma, JH Sun and BY Yin. (2009). Isolation and culture of bovine mammary epithelial stem cells. J Vet Med Sci 71:15-19.

25. Martignani E, P Eirew, C Eaves and M Baratta. (2009). Functional identification of bovine mammary epithelial stem/progenitor cells. Vet Res Commun 33 Suppl 1:101-103.

26. Capuco AV. (2007). Identification of putative bovine mammary epithelial stem cells by their retention of labeled DNA strands. Exp Biol Med 232:1381-1390.

27. Capuco AV, CM Evock-Clover, A Minuti and DL Wood. (2009). In vivo expansion of the mammary stem/progenitor cell population by xanthosine infusion. Exp Biol Med 234: 475-482.

28. Davies Morel MCG. (2008). The Anatomy and Physiology of Lactation. Equine Reproductive Physiology, Breeding and Stud Management, 3rd edn. Oxford University Press, USA, pp 84-85.

29. Leadon DP, LB Jeffcott and PD Rossdale. (1984). Mammary secretions in normal spontaneous and induced premature parturition in the mare. Equine Vet J 16:256-259.

30. Ousey JC, F Dudan and PD Rossdale. (1984). Preliminary studies of mammary secretions in the mare to assess foetal readiness for birth. Equine Vet J 16:259-263.

31. Dontu G, WM Abdallah, JM Foley, KW Jackson, MF Clarke, MJ Kawamura and MS Wicha. (2003). In vitro propagation and transcriptional profiling of human mammary stem/ progenitor cells. Genes Dev 17:1253-1270.

32. Rauner G and I Barash. (2012). Cell hierarchy and lineage commitment in the bovine mammary gland. PloS One 7:e30113.

33. Smith GH. (2006). Mammary stem cells come of age, prospectively. Trends Mol Med 12:287-289.
34. Stingl J. (2009). Detection and analysis of mammary gland stem cells. I Pathol 217:229-241.

35. Spaas JH, C De Schauwer, P Cornillie, E Meyer, A Van Soom and GR Van de Walle. (2012). In vitro culture and characterization of equine peripheral blood mesenchymal stromal cells. Vet J. [Epub ahead of print]; DOI: 10.1016/j.tvj1.2012 .05 .006

36. De Schauwer C, E Meyer, P Cornillie, S De Vliegher, GR van de Walle, M Hoogewijs, H Declercq, J Govaere, K Demeyere, M Cornelissen and A Van Soom. (2011). Optimization of the isolation, culture, and characterization of equine umbilical cord blood mesenchymal stromal cells. Tissue Eng Part C Methods 17:1061-1070.

37. Booth BW, CA Boulanger, LH Anderson, L Jimenez-Rojo, C Brisken and GH Smith. (2010). Amphiregulin mediates self-renewal in an immortal mammary epithelial cell line with stem cell characteristics. Exp Cell Res 316:422-432.

38. Farnie G, RB Clarke, K Spence, N Pinnock, K Brennan, NG Anderson and NJ Bundred. (2007). Novel cell culture technique for primary ductal carcinoma in situ: role of Notch and epidermal growth factor receptor signaling pathways. J Natl Cancer Inst 99:616-627.

39. Cregan MD, Y Fan, A Appelbee, ML Brown, B Klopcic, J Koppen, LR Mitoulas, KM Piper, MA Choolani, YS Chong and PE Hartmann. (2007). Identification of nestin-positive putative mammary stem cells in human breastmilk. Cell Tissue Res 329:129-136.

40. Hu H, J Wang, D Bu, H Wei, L Zhou, F Li and JJ Loor. (2009). In vitro culture and characterization of a mammary epithelial cell line from Chinese Holstein dairy cow. PloS One 4:e7636.

41. Zhao X, GK Malhotra, SM Lele, MS Lele, WW West, JD Eudy, H Band and V Band. (2010). Telomerase-immortalized human mammary stem/progenitor cells with ability to selfrenew and differentiate. Proc Natl Acad Sci U S A 107:14146-14151.

42. Nombela-Arrieta C, J Ritz and LE Silberstein. (2011). The elusive nature and function of mesenchymal stem cells. Nat Rev Mol Cell Biol 12:126-131.

43. Sternlicht MD. (2006). Key stages in mammary gland development: the cues that regulate ductal branching morphogenesis. Breast Cancer Res 8:201.

44. Forsyth IA. (1986). Variation among species in the endocrine control of mammary growth and function-the roles of prolactin, growth-hormone, and placental-lactogen. J Diary Sci 69:886-903.

45. Lamote I, E Meyer, AM Massart-Leen and C Burvenich. (2004). Sex steroids and growth factors in the regulation of mammary gland proliferation, differentiation, and involution. Steroids 69:145-159.

46. Coates PJ, SA Hales and PA Hall. (1996). The association between cell proliferation and apoptosis: studies using the cell cycle-associated proteins Ki67 and DNA polymerase alpha. J Pathol 178:71-77.

47. Pitelka DR, ST Hamamoto, JG Duafala and MK Nemanic. (1973). Cell contacts in the mouse mammary gland. I. Normal gland in postnatal development and the secretory cycle. I Cell Biol 56:797-818.

48. Capuco AV, SE Ellis, SA Hale, E Long, RA Erdman, X Zhao and MJ Paape. (2003). Lactation persistency: insights from mammary cell proliferation studies. J Anim Sci 81 Suppl 3:18-31.

49. Stingl J, P Eirew, I Ricketson, M Shackleton, F Vaillant, D Choi, $\mathrm{HI} \mathrm{Li} \mathrm{and} \mathrm{CJ} \mathrm{Eaves.} \mathrm{(2006).} \mathrm{Purification} \mathrm{and} \mathrm{unique} \mathrm{proper-}$ ties of mammary epithelial stem cells. Nature 439:993-997. 
50. Sun P, Y Yuan, A Li, B Li and X Dai. (2010). Cytokeratin expression during mouse embryonic and early postnatal mammary gland development. Histochem Cell Biol 133: 213-221.

51. Stingl J, CJ Eaves, U Kuusk and JT Emerman. (1998). Phenotypic and functional characterization in vitro of a multipotent epithelial cell present in the normal adult human breast. Differentiation 63:201-213.

52. Hermann A, R Gastl, S Liebau, MO Popa, J Fiedler, BO Boehm, M Maisel, H Lerche, J Schwarz, R Brenner and A Storch. (2004). Efficient generation of neural stem cell-like cells from adult human bone marrow stromal cells. I Cell Sci 117:4411-4422.

53. Ghaedi M, M Soleimani, I Shabani, Y Duan and AS Lotfi. (2012). Hepatic differentiation from human mesenchymal stem cells on a novel nanofiber scaffold. Cell Mol Biol Lett 17:89-106.

54. Murphy S, S Rosli, R Acharya, L Mathias, R Lim, E Wallace and $G$ Jenkin. (2010). Amnion epithelial cell isolation and characterization for clinical use. Curr Protoc Stem Cell Biol Chapter 1:Unit 1E.6.

55. Khuong TT and DK Jeong. (2011). Adipogenic differentiation of chicken epithelial oviduct cells using only chicken serum. In Vitro Cell Dev Biol Anim 47:609-614.

56. De Schauwer C, S Piepers, GR Van de Walle, K Demeyere, MK Hoogewijs, JL Govaere, K Braeckmans, A Van Soom and E Meyer. (2012). In search for cross-reactivity to immunophenotype equine mesenchymal stromal cells by multicolor flow cytometry. Cytometry A 81:312-323.

57. Semon JA, LH Nagy, CB Llamas, HA Tucker, RH Lee and DJ Prockop. (2010). Integrin expression and integrin-mediated adhesion in vitro of human multipotent stromal cells (MSCs) to endothelial cells from various blood vessels. Cell Tissue Res 341:147-158.

58. Deshiere A, E Duchemin-Pelletier, E Spreux, D Ciais, C Forcet, C Cochet and O Filhol. (2011). Regulation of epithelial to mesenchymal transition: CK2beta on stage. Mol Cell Biochem 356:11-20.
59. van Os R, LM Kamminga and G de Haan. (2004). Stem cell assays: something old, something new, something borrowed. Stem Cells 22:1181-1190.

60. Barrandon Y and H Green. (1987). Cell-migration is essential for sustained growth of keratinocyte colonies-the roles of transforming growth factor-alpha and epidermal growthfactor. Cell 50:1131-1137.

61. Barrandon Y and H Green. (1987). Three clonal types of keratinocyte with different capacities for multiplication. Proc Natl Acad Sci U S A 84:2302-2306.

62. Visvader JE and GJ Lindeman. (2006). Mammary stem cells and mammopoiesis. Cancer Res 66:9798-9801.

63. Stingl J, A Raouf, P Eirew and CJ Eaves. (2006). Deciphering the mammary epithelial cell hierarchy. Cell Cycle 5:15191522.

64. Welm BE, SB Tepera, T Venezia, TA Graubert, JM Rosen and MA Goodell. (2002). Sca-1(pos) cells in the mouse mammary gland represent an enriched progenitor cell population. $\underline{\text { Dev }}$ Biol 245:42-56.

65. Smith GH and D Medina. (2008). Re-evaluation of mammary stem cell biology based on in vivo transplantation. Breast Cancer Res 10:203.

Address correspondence to: Prof. Gerlinde R. Van de Walle Department of Comparative Physiology and Biometrics Faculty of Veterinary Medicine Ghent University Merelbeke 9820 Belgium

E-mail: gerlinde.vandewalle@ugent.be

Received for publication January 27, 2012

Accepted after revision May 10, 2012

Prepublished on Liebert Instant Online May 11, 2012 
This article has been cited by:

1. Bizunesh M. Borena, Leen Bussche, Christian Burvenich, Luc Duchateau, Gerlinde R. Van de Walle. 2013. Mammary Stem Cell Research in Veterinary Science: An Update. Stem Cells and Development 22:12, 1743-1751. [Abstract] [Full Text HTML] [Full Text PDF] [Full Text PDF with Links] 